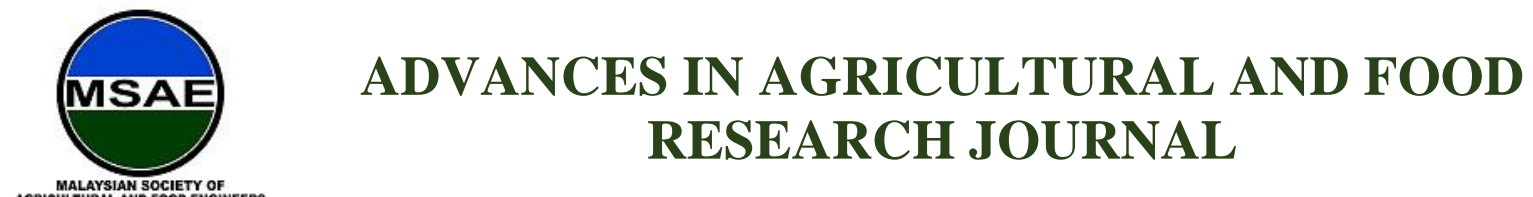

Original Research Article

\title{
Automated Controlled Environment Mushroom House
}

Ten Seng Teik ${ }^{1 *}$, Ganisan Krishnen ${ }^{2}$, Khairul Asfamawi Khulidin² ${ }^{2}$, Muhd Akhtar Mohamad Tahir ${ }^{1}$, Mohamad Hafiz Hashim $^{1}$, Syaliyana Khairudin ${ }^{2}$

${ }^{1}$ Engineering Research Centre, Malaysian Agricultural Research and Development Institute (MARDI), 43400 Serdang, Selangor, Malaysia, stten@mardi.gov.my

${ }^{2}$ Soil Science, Water and Fertilizer Research Centre, Malaysian Agricultural Research and Development Institute (MARDI), 43400 Serdang, Selangor, Malaysia, ganisan@mardi.gov.my

*Corresponding author: Ten Seng Teik, Engineering Research Centre, Malaysian Agricultural Research and Development Institute (MARDI), 43400 Serdang, Selangor, Malaysia, stten@ mardi.gov.my

Abstract: Mushroom can be served as flavoursome food, but most importantly, it can be served as nutritional and medicinal value food. Therefore, mushroom is an essential commodity under the Malaysia National Agro-Food Policy. Currently, mushroom cultivation is being done in the conventional method, not in a proper and hygienic condition. Therefore controlled environment mushroom house (CEMH) has been developed by transforming a greenhouse into a controlled environment mushroom house integrated with the internet of things (IoT) system. This CEMH micro-climate is automatically controlled by the combination of data parameters provided by various types of sensors. The integration of the IoT system has further enhanced this system to overcome extreme weather changes and override the control anytime and anywhere. The computation and monitoring process can be done either locally or remotely. The current system is set up for Grey Oyster mushroom (Pleurotus pulmonaris) cultivation to identify the best isolate to be proposed for mass production. The interconnection of sensors, mechanical and electronic systems is to optimize the growth condition. The developed system manages to control the temperature consistently and relative humidity ( $\% \mathrm{RH})$ in the range of $18^{\circ} \mathrm{C}$ to $27^{\circ} \mathrm{C}$ and $\% \mathrm{RH}$ not lower than $70 \%$, respectively. For this condition, this system can produce at least $30 \%$ more yield than ordinary mushroom houses. Moreover, the contamination rate is successfully kept below $2 \%$ and is considered very low compared to ordinary entrepreneur mushroom houses, usually more than $10 \%$. This system can provide the research facility for the high nutritional and medicinal value mushrooms.

Keywords: controlled environment; micro-climate; internet of things; greenhouse; Pleurotus pulmonaris

Received: $25^{\text {th }}$ July 2021

Citation: Teik TS, Krishnen G, Khulidin $\mathrm{KA}$, et al. Automated controlled environment mushroom house. Adv Agri Food Res J 2021; 2(2): a0000230.

Received in revised form: https://doi.org/10.36877/aafrj.a0000230

Accepted: $25^{\text {th }}$ August 2021

Available Online: $14^{\text {th }}$ September 2021 


\section{Introduction}

The world population is estimated to be about 9.7 billion in 2050 (Max, 2013). Thus, food production will have to be significantly increased to support the population. In addition to this, human beings also face problems of diminishing natural resources and lands, global warming, and unpredictable weather conditions, which make food security a primary concern globally. Mushrooms have been served as food and medicine for the last few decades. Currently, the usage of mushrooms has expanded up beyond food and in the area of pharmaceuticals, nutraceuticals, and cosmeceuticals (Himanshi et al., 2017). Approximately 35 edible mushroom species are commercially cultivated, whereas nearly 200 wild species have been used for medicinal purposes (Beulah et al., 2013). Mushrooms contain $50 \%$ to $65 \%$ total carbohydrate, $19 \%$ to $35 \%$ proteins (with various biological and medicinal activities such as lectins), and $2 \%$ to $6 \%$ fat content of their dry matter (Rathore et al., 2017). Mushrooms rich in fat-soluble vitamins and ergosterol content are thought to be the only vegetarian source for vitamin D (Aida et al., 2009). Therefore, the mushrooms industry is considered one of the most booming industries. From those domesticated and commercially grown mushrooms, the best-known specialty mushroom and most manageable to market is Oyster mushrooms and Shiitake (Barney, 2015). Oyster mushrooms are a diverse group of saprotrophic fungi belonging to Pleurotus (Kong, 2004). The protein content varies from 1.6 to $2.5 \%$, and the niacin content is about ten times higher than that of any other vegetable (Ahmed et al., 2016). Moreover, oyster mushrooms have been reported rich in Vitamin C, B complex, and the mineral salts required by the human body (Randive, 2012). Mushroom production in rural communities can alleviate poverty, for instance, developing young agropreneur (Khairul, 2015).

The demand for mushrooms in Malaysia is projected to increase, and the demand is estimated to increase from 20,000 tonnes in 2008 to around 48,000 tonnes in 2020. The demand for grey mushrooms is greater or over than supply production in Malaysia. This has led Malaysia has to import fresh and processed mushrooms from other countries (Islam et al. 2016). Malaysia imported 2.71 million tonnes of fresh mushrooms valued at more than RM 6.2 million and 3.11 million tonnes of dried mushrooms valued at more than RM 11.99 million from China in 2012. The import of mushrooms from China increased steadily at an annual average of $9.23 \%$ for the fresh ones and $12.93 \%$ for the dried ones from 2009 (Amin et al., 2014).

Moreover, local mushroom industries are facing challenges, such as enhancing yield, quality of spawn or good mushroom seed (mycelium), green fungus diseases, and pest attack (rats, ants, lizards, and cockroaches) (Haimid et al., 2013; Rosmiza et al., 2016). In addition, the natural environmental conditions of Malaysia or in similar regions are not suitable for indoor mushrooms cultivation due to its low humidity and high temperature (Islam et al., 2016). In the environmental profile of Malaysia, it must need to apply any artificial system to provide an optimum growing environment for mushrooms (Islam et al., 2016). However, most of the controlled environment mushroom house researches in Malaysia (Kassim et al., 
2017; Marzuki \& Ying 2017; Mohammed et al., 2018; Kassim et al., 2019) are mainly for controlling the relative humidity condition and not so much for the temperature control, only using fans and misting for reducing the temperature (not more than $3^{\circ} \mathrm{C}$ different between controlled and non-controlled environment). Even with controlled humidity, the contamination rate can research as high as 30\% (Islam et al., 2017). IoT systems combined with data analytics have been currently used in agriculture worldwide to meet the world's food demands in the coming years (Dlodlo \& Kalezhi, 2015). IoT device installations in the agriculture sector were predicted to increase from 30 million in 2015 to 75 million by 2020 (Elijah et al., 2018). There are challenges in mushroom cultivation, such as a lack of skills in mushroom cultivation and less quality of mushroom production (Ibrahim et al., 2018). Utilizing IoT technology, which consists of sensors and feedback systems, will optimize climate conditions for optimum growth of mushrooms (Ibrahim et al., 2018). For the study to prove that that temperature (which is controlled by the air-conditioning system and not by fans) and humidity can reduce the contamination rate and increase the yield, an automatic IoT controlled environment mushroom house (CEMH) is developed especially for the sudden weather change which is usually happening in Malaysia. Oyster mushrooms were selected for this study. The substrate and mushroom strains were standardized for the experiments carried out in the non-controlled and controlled environments as different mushroom strains also have different growth and yield performance (Dundar et al., 2008).

\section{Materials and Methods}

The CEMH was transformed from a controlled environmental greenhouse. Development of CEMH and facilities are for the production of high-quality selected mushrooms and seeds in MARDI to provide good quality and diseases resistance spawn for the local mushroom industries. CEMH is an automatic IoT building where environmental parameters can be controlled and manipulated to suit the growth of mushrooms. This project focuses on developing the CEMH technology as proof of concept in meeting modern and prolific agricultural production needs, specifically for selected mushroom production and quality mushroom seed production. The development of this technology enables the mushrooms to be produced in a state of growth that is manipulated independently of the diversity of the external environment. The system facilitates the research to screen and identify the best strains of Grey Oyster mushroom (Pleurotus pulmonaris) available in MARDI.

$\mathrm{CEMH}$, developed is the controlled environment mushroom house integrated with components of Industry Revolution 4.0 (IR 4.0) technological pillars; internet of things (IoT) system and cloud computing. The IoT system and cloud computing were set up with the assistance of Signal Transmission (M) Sdn Bhd. Figure 1 shows an overall system of CEMH. Advantech ADAM-3600, a remote terminal unit (RTU), is implemented as a microprocessorcontrolled electronic device with built-in software called Edgelink (one type of the supervisory control and data acquisition (SCADA) software) that interfaces objects in the 
physical world to a distributed control system or SCADA system by transmitting telemetry data to a master system, and by using messages from the master supervisory system to control connected objects. This RTU supports the local raw data translation and digitizes the raw analog data sent by the sensors by using Modbus communication protocols. For that, it communicates and receives information from light meters (providing light intensity information inside the building), humidity meters (providing relative humidity information inside the building), thermocouple temperature sensors (providing temperature information inside the building), and $\mathrm{CO}_{2}$ meters (providing $\mathrm{CO}_{2}$ concentration information inside the building). After ADAM-3600 has gathered all the input/output (I/O) reading from another module (sensors and meters), it converts the raw data from the sensors to Message Queuing Telemetry Transport (MQTT) protocol. It sends the data to the cloud or Virtual Machine (VM) (in the cloud server) through Global System for Mobile Communications (GSM) network. This virtual machine runs in Microsoft Azure Portal with built-in software called WebAccess/SCADA, a web-based SCADA software application. WebAccess/SCADA is Advantech's core IoT application platform. It provides a unique environment for development and remote maintenance, allowing access to and manipulating data stored on the cloud (Virtue Machine or central server). The data which is sent by ADAM-3600 to the cloud will be stored in PostgreSQL databases. Once the data reaches the cloud database, the data can be displayed using Dashboards (WebAccess App) shown in Figure 1. The data can be sent to Dropbox using WebAccess/SCADA from Virtue Machine or Edgelink from ADAM-3600 software's scripting to write code to save certain logged data as a CSV format file for easy access.

Besides that, ADAM-3600 acts as a program logic controller (PLC) to control the equipment in this system. The equipment includes rooftop ventilation fans, misting system (20-40 $\mu \mathrm{m}$ size water droplets), and an air conditioning system (four units $12.5 \mathrm{HP}$ ). Rooftop ventilation fans remove the hot air from the building, create air flow, avoid the air becoming stagnant, and reduce the $\mathrm{CO}_{2}$ level below $600 \mathrm{ppm}$. The misting system maintains the pre-set air wetness inside the mushroom house, whereas the air conditional system controls the air temperature inside the mushroom house. ADAM-3600 has a quick and easy connectionfriendly user function. It lets users see all the reading and control the equipment using their remote devices like handphones or tablets by logging in to the WebAccess App platform. All the data from the $\mathrm{I} / \mathrm{O}$ reading from a light meter, humidity meter, thermocouple temperature sensor, and $\mathrm{CO}_{2}$ meter are stored in Dropbox and backed up in ADAM-3600 as well. 


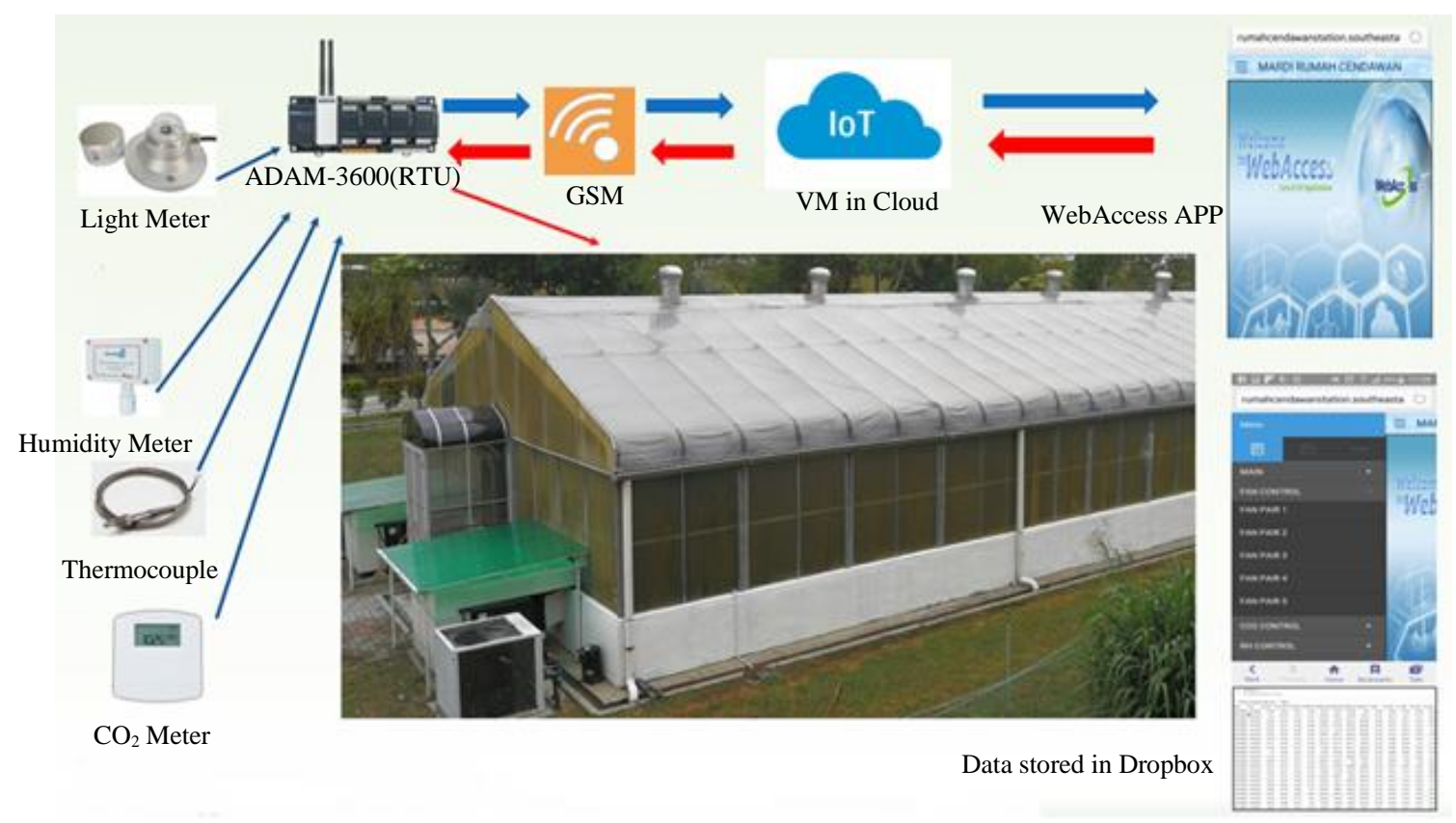

Figure 1. Overview IoT system for the smart mushroom house.

With the enhancement of the IoT system, the CEMH micro-climate is automatically controlled by the ADAM-3600, conditional air system, misting system, and rooftop ventilation system with the combination data parameters provided by various types of sensors. The system can be overridden anytime remotely to pursue the interconnection of machines and systems for being the intelligent farming system to overcome the unpredictable extreme weather changes. The developed system is capable to consistently control the temperature and humidity in the range of $18^{\circ} \mathrm{C}$ to $27^{\circ} \mathrm{C}$ and relative humidity (RH) not lower than $70 \%$ respectively and light intensity in the range of 8-500 Lux, where 15-350 Lux is suitable for various varieties mushrooms (Kibar \& Peksen, 2008). For these conditions, the intelligent mushroom house can cater to the growing research of various kinds of mushrooms, as shown in Table 1.

Table 1. Growing condition for different variety mushrooms.

\begin{tabular}{ccc}
\hline Mushroom Type & $\begin{array}{c}\text { Temperature } \\
\text { ( } \mathbf{C})\end{array}$ & $\begin{array}{c}\text { Relative Humidity, } \\
\text { RH (\%) }\end{array}$ \\
\hline King Oyster (Pleurotus eryngii) (Ryu et al., 2015) & $15-22$ & $65-95$ \\
\hline $\begin{array}{c}\text { Black Jelly Mushroom (Auricularia auricula-judae) (Priya et } \\
\text { al.,2016) }\end{array}$ & $25-26$ & $85-90$ \\
\hline $\begin{array}{c}\text { Grey Oyster Mushroom (Pleurotus pulmonaris) (Stanley et al., } \\
\text { 2011) }\end{array}$ & $25-28$ & $80-85$ \\
\hline
\end{tabular}

Different types of substrate materials can influence the mushroom growth and yield performance, and the substrate weight can also contribute to the mushroom yield by the biological efficiency (Sharma et al., 2013). Other than that, different mushroom strains also 
have different growth and yield performance (Dundar et al., 2008). In order to prove that the temperature and humidity control can reduce the contamination rate and increase the yield, the same standard of substrate preparation, Grey (Pleurotus pulmonaris) and White (Pleurotus florida) Oyster mushroom spawn were used in $\mathrm{CEMH}$ and non-controlled environments, Jenjarom and MARDI Klang, Selangor as ordinary mushroom houses. The preparation of the mushroom substrate bag was done at $\mathrm{CEMH}$, Engineering Research Centre, MARDI Headquarters Serdang, Selangor. Mushroom substrate bag preparation was according to the pre-set standard (Khairul et al., 2012). The sawdust, rice bran, and lime were mixed (in the ratio of 100:10:1). The mixtures were added to water and made dense. $650 \pm 50$ $\mathrm{g}$ of substrate mixture was fill in each autoclavable polypropylene plastic $(6 \times 9$ inches $)$ bag and covered with a PVC cap to protect loss of moisture content from inside the bags (Islam et al., 2016). Five hundred mushroom substrate bags were steamed at $95 \pm 3^{\circ} \mathrm{C}$ in steamer 5 hours before use. Inoculation of oyster mushroom spawn was done aseptically. Each experiment was replicated four times. Grey (P. pulmonaris) and White (P. florida) Oyster mushroom spawns were obtained from Spawn Laboratory, Soil Science, Water, and Fertilizer Research Centre, MARDI Headquarters Serdang, Selangor. Statistical Analysis, Descriptive statistics were applied to find maximum, minimum, mean, and standard deviation (SD) in all collected data.

As the current system is set up for identification, the best $P$. pulmonaris isolate cultivation is proposed for mass production. Thus, the controlled temperature and relative humidity ranges are set between $21^{\circ} \mathrm{C}$ to $27^{\circ} \mathrm{C}$, and the $\% \mathrm{RH}$ is not lower than $70 \%$, respectively. The temperature in $\mathrm{CEMH}$ is controlled by the four-unit $12.5 \mathrm{HP}$ air conditional system and is based on the Specific Air-space Stratification Techniques (SAST) (Ismail, 2006). The cool air is channeled to CEMH through underground dusting. This method has the advantage of maintaining the optimum growing temperature range at the mushroom growing area from the ground level and at the same time avoiding direct heat contact with the hot air from the top. The misting system controls the relative humidity in CEMH (20-40 $\mu \mathrm{m}$ size water droplets). The light intensity is set below 350 Lux by closing the almost $90 \%$ light transmission around the building. The $\mathrm{CO}_{2}$ level is kept below $600 \mathrm{ppm}$ by the rooftop ventilation system to suit the optimum growing condition for $P$. pulmonaris.

\section{Results}

The comparison results of temperature and relative humidity between control and non-controlled environments are shown in Figure 2 and Figure 3, respectively. Figure 2 shows that the maximum temperature outside a non-controlled environment could reach as high as $35.2^{\circ} \mathrm{C}$, minimum of $24.4^{\circ} \mathrm{C}$ and an average of $28.6^{\circ} \mathrm{C}$ and standard deviation (SD) of $3.24^{\circ} \mathrm{C}$, which is high and vast vary between day time and night time. Figure 2 also shows the maximum temperatures for the controlled environment were $24.4^{\circ} \mathrm{C}$ and $26.3^{\circ} \mathrm{C}$ at the height of $1.0 \mathrm{~m}$ and $1.5 \mathrm{~m}$, respectively, whereas the minimum temperature of $21.2^{\circ} \mathrm{C}$ for both heights in CEMH. It shows that the system can maintain average temperatures $22.16^{\circ} \mathrm{C}$ (SD of $0.71^{\circ} \mathrm{C}$ ) and $22.65^{\circ} \mathrm{C}\left(\mathrm{SD}\right.$ of $\left.1.17^{\circ} \mathrm{C}\right)$ at the height of $1.0 \mathrm{~m}$ and $1.5 \mathrm{~m}$, respectively $\mathrm{CEMH}$ 
and achieved the pre-set temperatures with very small vary when compared with the noncontrolled environment. Figure 3 shows the lowest $\% \mathrm{RH}$ for the non-controlled environment was as low as $53.87 \%$ with an average of $63.00 \%$ (SD of $5.03 \%$ ), which is very dry and with SD of $5.03 \%$ is considered vast vary compared to SD of $1.76 \%$ in the controlled environment. The lowest \% RH in controlled environment mushroom house was $70.32 \%$, with average RH at $73.71 \%$ (SD of $1.76 \%$ ) during the daytime hot and dry condition, proving that the system could maintain according to the pre-set relative humidity, not lower than $70 \%$.

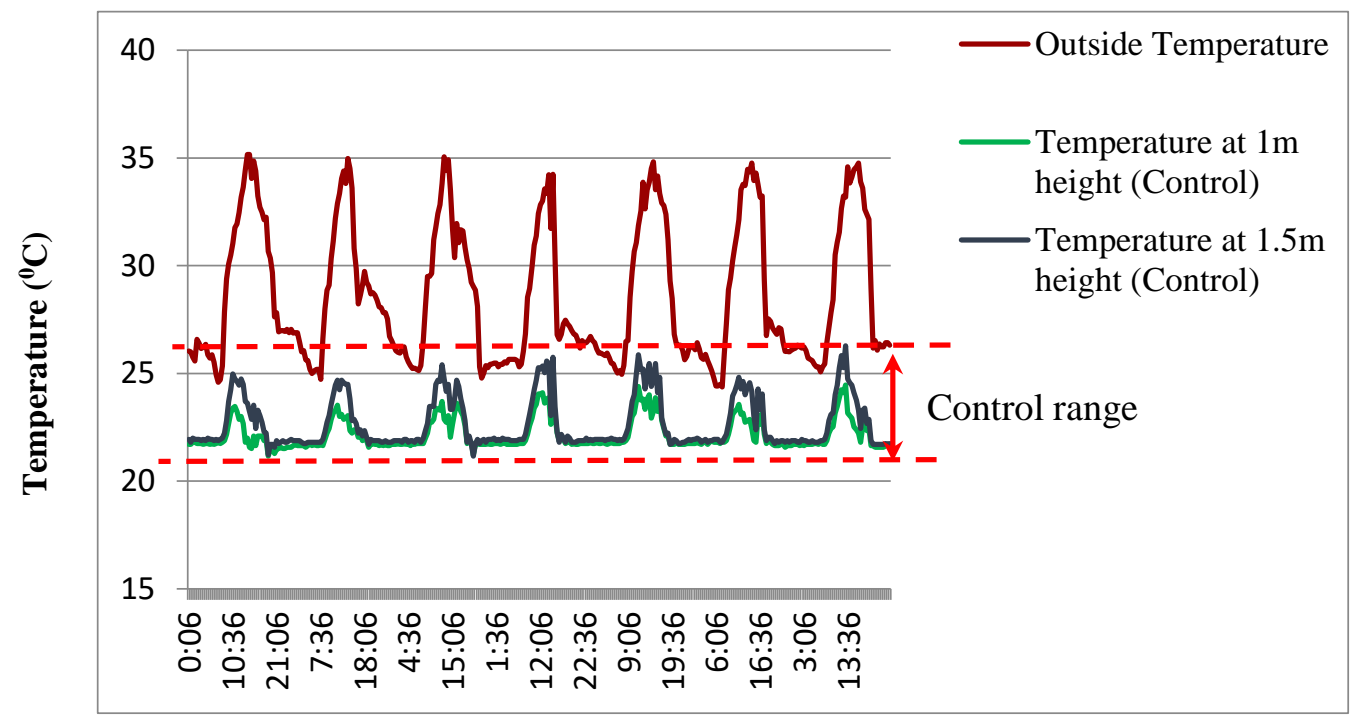

Time

Figure 2. Temperature comparison between outside and inside smart CEMH (control).

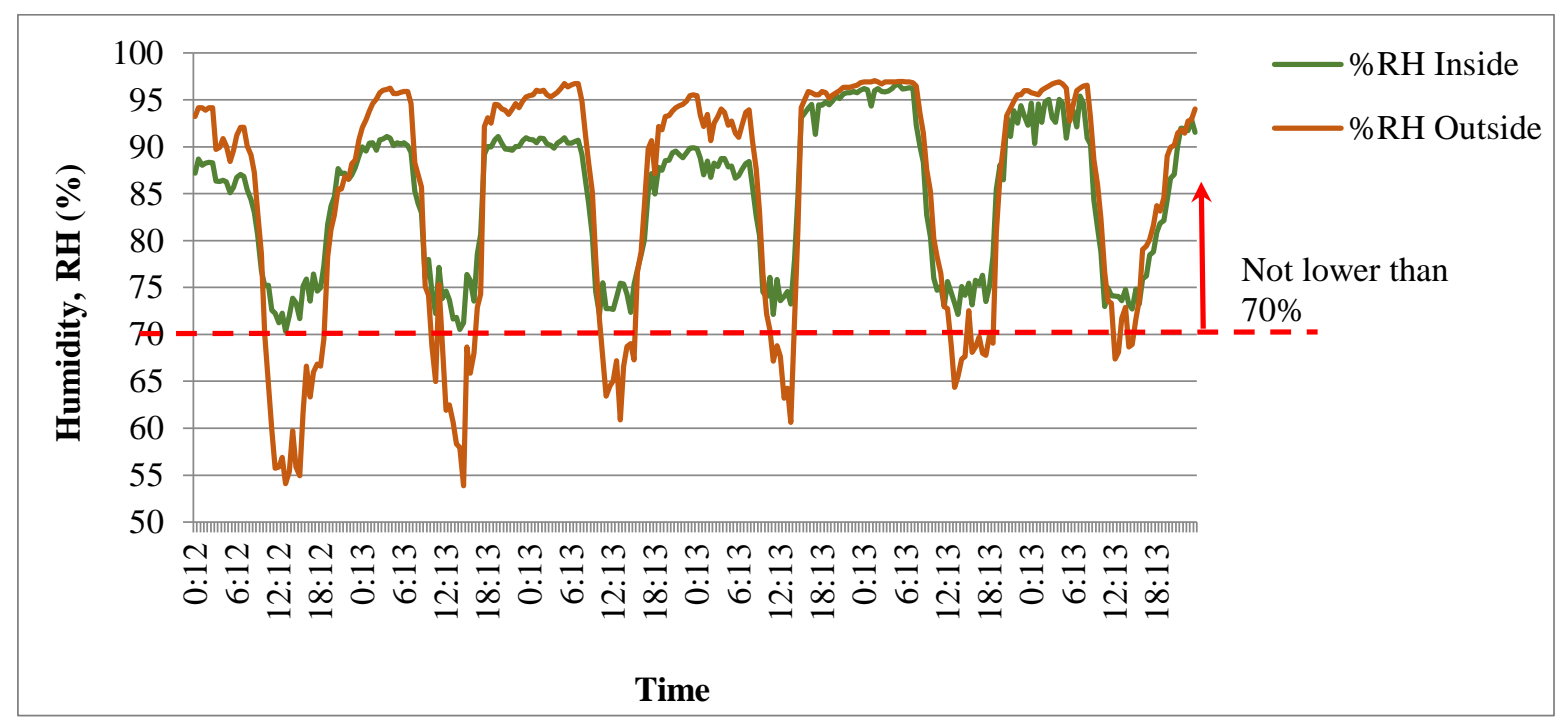

Figure 3. Relative humidity (\%RH) comparison between outside and inside CEMH (control).

The effects of the non-controlled and control system on the growth of the mushrooms are shown in Figure 4 and Figure 5. The non-controlled environments were done in Jenjarom and MARDI Klang as ordinary mushroom houses. The controlled environment was done in 
CEMH. Figure 4 shows the average yields of mushrooms on different mushrooms and spawns either in grain or liquid form in non-controlled and controlled environments. The highest average yield of mushrooms was shown in CEMH compared to Jenjarom and MARDI Klang mushroom houses. CEMH produced 30\% significantly higher (average of $149.1 \mathrm{~g} / \mathrm{bag}$ with SD of $2.32 \mathrm{~g}$ ) mushroom yield growth compared to other mushroom houses, which Jenjarom obtained an average of $114.3 \mathrm{~g} / \mathrm{bag}$ with an SD of $2.12 \mathrm{~g}$. In contrast, MARDI Klang obtained an average of $98.2 \mathrm{~g} / \mathrm{bag}$ with an SD of $1.96 \mathrm{~g}$ for the Grey Oyster Mushroom.

Moreover, CEMH also managed to produce more than $115 \mathrm{~g} / \mathrm{bag}$ of the White Oyster mushrooms regardless of the types of spawns. Figure 5 shows the lowest contamination percentage of the mushroom bag, less than $2 \%$ of bag contamination in CEMH compared to Jenjarom grower (11.32\%) and MARDI Klang (3.17\%) mushroom house. The condition in CEMH was also able to keep the contamination rate less than $2 \%$ for the White Oyster and Grey Oyster mushrooms regardless of the different spawns, either in grain or liquid form.

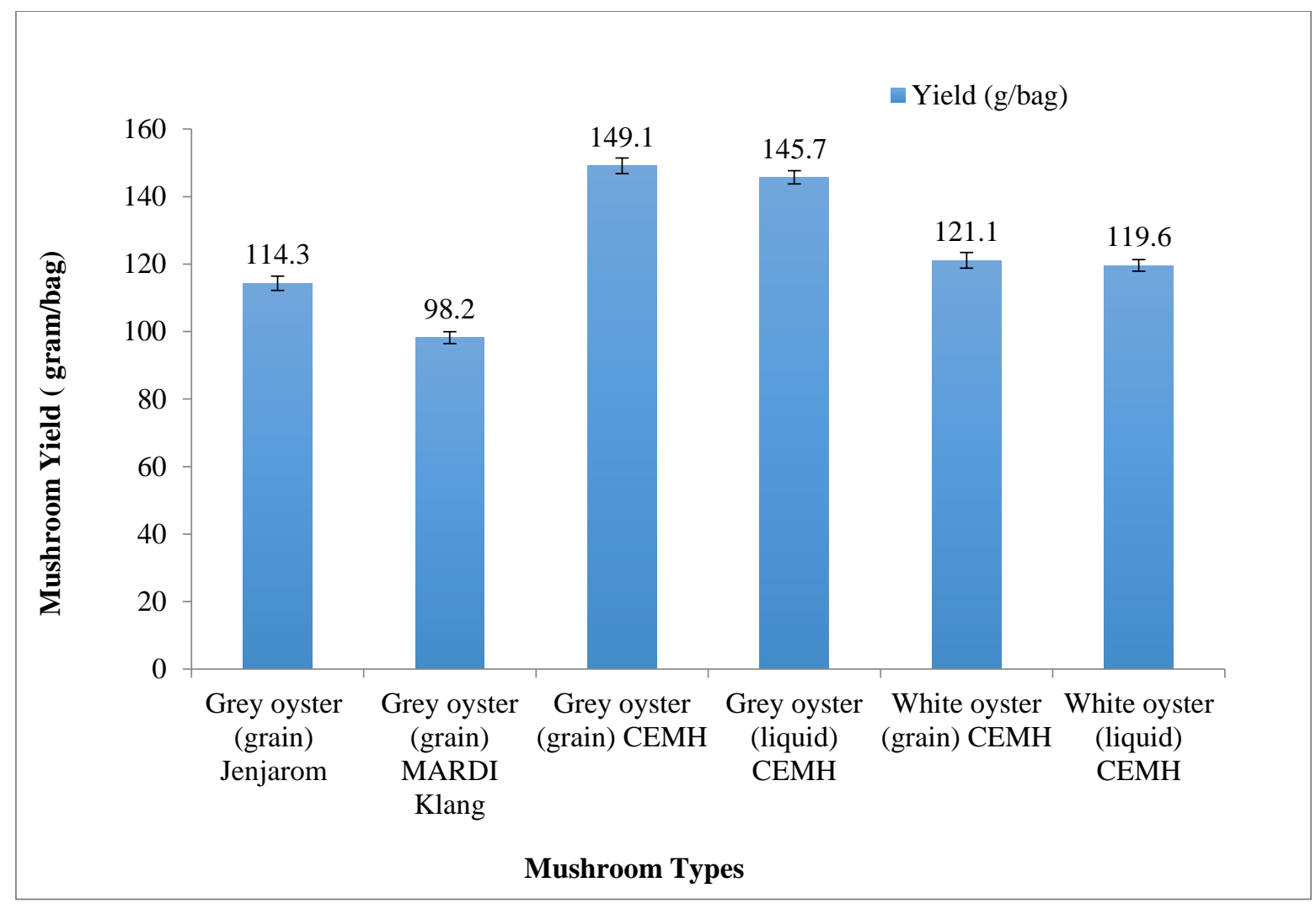

Figure 4. An average yield of mushrooms on different types and spawn (liquid and grain) of mushrooms at various mushroom houses. 


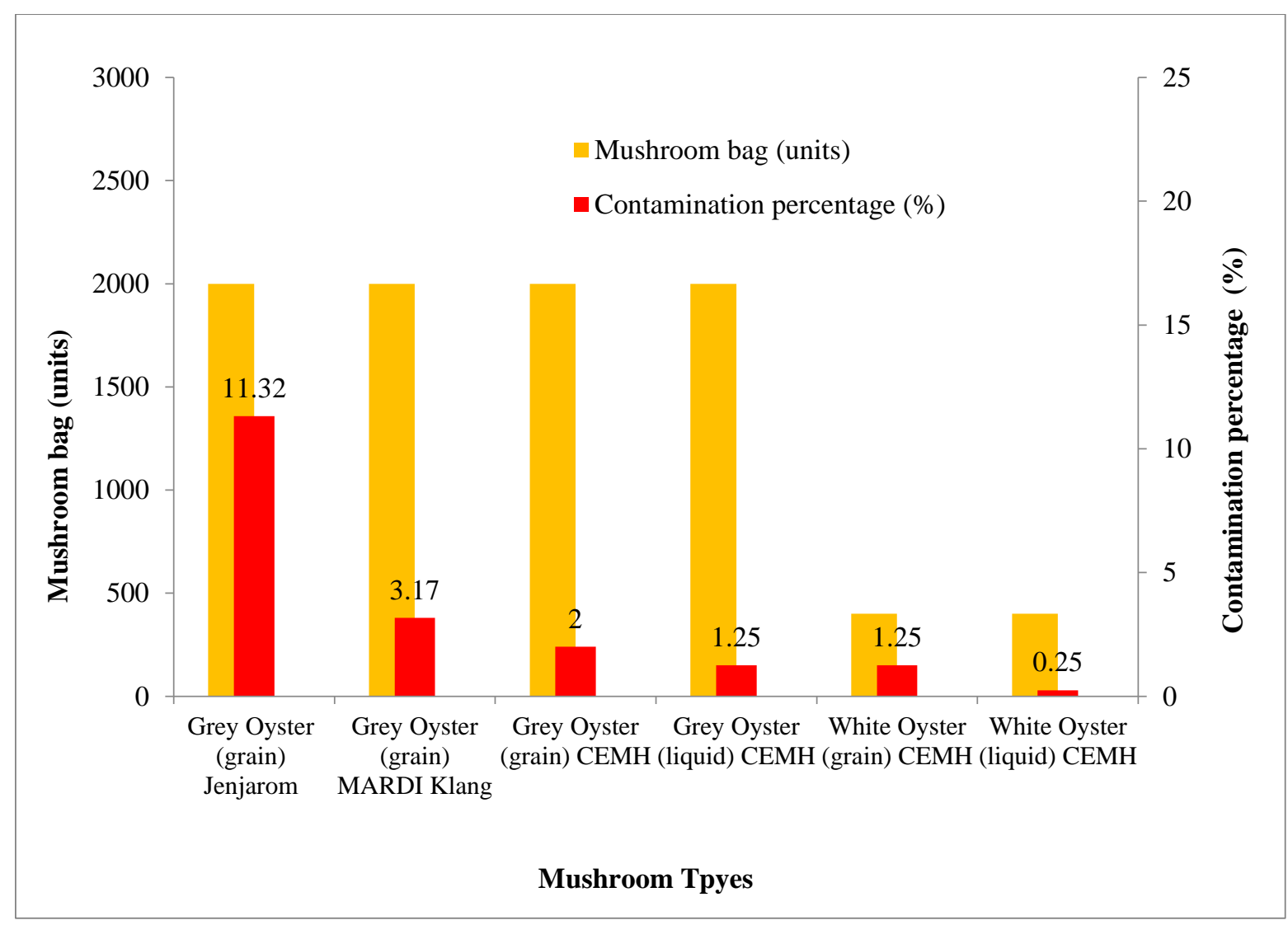

Figure 5. Comparison of contamination percentage of the mushroom bag on different types and spawn of mushrooms at various mushroom houses.

\section{Discussion}

The results in Figure 2 and Figure 3 show that CEMH managed to control the microclimate of the mushroom house even under the substantially different temperatures between the hot and dry day and night time. In the typical mushroom house (without a controlled environment), the temperature could reach a maximum of $35.2^{\circ} \mathrm{C}$ and an average of $28.6^{\circ} \mathrm{C}$, which had already exceeded the optimum growth temperature for Grey Oyster mushroom stated in Table 1. On the other hand, the CEMH had shown the ability to maintain average temperatures $22.16^{\circ} \mathrm{C}\left(\mathrm{SD}\right.$ of $0.71^{\circ} \mathrm{C}$ ) and $22.65^{\circ} \mathrm{C}\left(\mathrm{SD}\right.$ of $\left.1.17^{\circ} \mathrm{C}\right)$ at the height of $1.0 \mathrm{~m}$ and $1.5 \mathrm{~m}$ respectively, with minimal variations and also in the range of maximum fruiting body condition as stated in the report Grey Oyster mushroom studies (Bano et al., 1982) which are $20^{\circ} \mathrm{C}$ to $26^{\circ} \mathrm{C}$. Grey Oyster mushrooms faced extreme dry stress in the non-controlled environment. The relative humidity could drop as low as $53.87 \%$ with an average of $63.00 \%$ (SD of $5.03 \%$ ), which is very dry compared to $\mathrm{CEMH}$, with an average $\mathrm{RH}$ at $73.71 \%$ (SD of $1.76 \%$ ) during the daytime hot and dry condition. Therefore, the Grey Oyster mushroom experienced high hot temperature and dryness stress in the non-controlled outside condition.

In contrast, the controlled environment mushroom house could maintain the relative humidity to suit the optimal growing condition, especially during the daytime hot and dry condition. Figure 4 proved that CEMH produced $30 \%$ significantly higher mushroom yield 
growth than non-controlled environment mushroom houses Jenjarom and MARDI Klang. Figure 5 further supports the advantage of CEMH in providing a better environment by showing the lowest contamination percentage (less than 2\%) of the mushroom bag compared to Jenjarom grower and MARDI Klang mushroom house. These results are also supported by the indoor Grey Oyster mushroom cultivation studies (Islam et al., 2016). The yield percentages and quality of $P$. pulmonarius increase with the increasing of indoor humidity and have a strong correlation among them.

\section{Conclusions}

The control system can control the CEMH ambient temperature and relative humidity for optimum growth conditions to overcome the relatively hot environment of Malaysia, which the temperature can rise to $41^{\circ} \mathrm{C}$ and the low relative humidity by $58 \%$ or even much lower during the hot season (Wafi et al., 2011) which is clear that temperature and humidity of Malaysia weather are far from the optimal condition for oyster mushroom cultivation. The farmers can also take corrective and preventive measures in advance based on the data provided and alarming status reports anywhere and anything sudden weather change to decide to override regular program basic to reduce the extreme environment change that will affect the mushroom productivity (Elijah et al., 2018). This research can help the local industries produce good quality various varieties mushroom spawns (seeds), especially for the popular, Grey Oyster Mushroom (P. pulmonaris) and reduce the imported especially for those have the high nutritional and medicinal value mushrooms. After achieving the proof of concept in reducing contamination and increasing yield, future works will be studying the minimum required commercial productivity scale to minimize the needed person-hours and, at the same time, maximize the profit margin. In the future, this IoT system aims to be applied in the supply chain as it will help provide real-time balancing between the demand and supply (Elijah et al., 2018) to prevent the losses of overproduced oyster mushrooms due to their short shelf life. This automated CEMH also provides the research facility to help the growers identify the most stable, good quality strain and the best isolate to be proposed for mass production.

Acknowledgements: The author wishes to thank all the co-authors for their cooperation to greatly improve this paper and highly appreciated Signal Transmission (M) Sdn. Bhd., MARDI, and all staff for their assistance during the progress of work.

Conflict of Interest: The authors declare no conflict of interest.

\section{References}

Ahmed, M., Noorlidah, A., Ahmed, K.U., et al. (2016). Yield and nutritional composition of oyster mushrooms: An alternative nutritional source for rural people. Sains Malaysiana, 45(11), 1609-1615.

Aida, F. M. N. A., Huhaim, M., Yazid, M., et al. (2009). Mushroom as a protential source of prebiotics: A Review. Trends in Food Science and Technology,20(11-12), 567-575

Amin, M. Z. M., Harun, A. \& Wahab, M. A. M. A. (2014). Status and potential of mushroom industry in Malaysia. Economic and Technology Management Review, 9, 103-111. 
Bano, Z. \& Rajaratham, S. (1982). Studies on the cultivation of Pleurotus sajor-caju. Journal of Mushroom, 1, 243-246.

Barney, D. L. (2015, May 15). Growing mushrooms commercially: Risks and opportunities. University of Idaho. http://www.cals.uidaho.edu.

Beulah, H., Margret, A. A., \& Nelson, J. (2013). Marvelous medicinal mushrooms. International Journal of Pharma and Bio Sciences,3(1), 611-615.

Dlodlo, N. \& Kalezhi, J. (2015). The internet of things in agriculture for sustainable rural development. 2015 International Conference on Emerging Trends in Networks and Computer Communications (ETNCC), IEEE.

Dundar, A., Acay, H., \& Yildiz, A. (2008). Yield performances and nutritional contents of three oyster mushroom species cultivated on wheat stalk. African Journal of Biotechnology, 7(19), 3497-3501.

Elijah, O., Rahman,T.A., Orikumhi, I., et al. (2018). An overview of Internet of Things (IoT) and data analytics in agriculture: Benefits and challenges. IEEE Internet of Things Journal, 5(5), 3758-3773.

Haimid, M. T., Rahim, H. \& Dardak, R. A. (2013). Understanding the mushroom industry and its marketing strategies for fresh produce in Malaysia. Economic and Technology Management Review, 8, 27-37.

Himanshi, R., Shalinee, P., \& Satyawati, S. (2017). Mushroom nutraceuticals for improved nutrition and better human health: A review. PharmaNutrition, 5, 35-46.

Ibrahim, N. H. N., Mat, I., Harun, A. N., et al. (2018). IR 4.0 using IoT and LORAWAN to accelerate lentinula edodes growth. 2018 2nd International Conference on Smart Sensors and Application (ICSSA), IEEE.

Islam, M. T., Zakaria, Z., Hamidin, N., et al. (2016). A competitive study on higher yield performance in indoor optimized environment and outdoor cultivation of Pleurotus pulmonarius. MAYFEB Journal of Agriculture Science, 2, 13-27.

Islam, M. T., Zakaria, Z., Hamidin, N., et al. (2016). Characteristics of indoor mushroom cultivation of grey oyster (Pleurotus pulmonarius) by different stages of humidifying treatment. World Applied Sciences Journal, 34(8), 1066-1075.

Islam, M. T., Zakaria, Z., Hamidin, N., et al. (2017). The management of humidifying treatment for low contamination risks during indoor cultivation of grey oyster mushroom (Pleurotus pulmonarius). MATEC Web of Conferences, 97, 01080.

Ismail, M. S. (2006, April 4-9). Stratified air-space method in design optimization of fully controlled environment greenhouse. $34^{\text {th }}$ International Exhibition of Inventions: New Techniques and Products of Geneva, Switzerland.

Kassim, M. R. M., Harun, A. N., Yusoff, I.M., et al. (2017). Applications of wireless sensor networks in Shiitake Mushroom cultivation. 2017 Eleventh International Conference on Sensing Technology (ICST), IEEE.

Kassim, M. R. M., Mat, I. \& Yusof, I.M. (2019). Applications of internet of things in mushroom farm management. 2019 13th International Conference on Sensing Technology (ICST), IEEE.

Khairul, A. K. (2015, May 26-28). Technology transfer for young generation entrepreneur through mardi youth agropreneur programme. 2015 FTCC - MARDI : International Seminar on Cultivating The Young Generation of Farmers with Farmland Policy Implications. MARDI Headquaters, Serdang, Selangor.

Khairul, A. K., Yasser, S. M., Mohamad, A. M., et al. (2012). Manual Teknologi Penanaman Cendawan Tiram Kelabu. Malaysian Agricultural Research and Development Institute (MARDI), Serdang, Selangor. 
Kibar, B. \& Peksen, A. (2008). Modelling the effects of temperature and light intensity on the development and yield of different Pleurotus species. Agricultura Tropica Et Subtropica, 41(2), 68-73.

Kong, W. S. (2004). Descriptions of commercially important Pleurotus species. In: K. W. Choi (Eds.), Mushroom Growers' Handbook 1: Oyster Mushroom Cultivation (pp. 54-61). Heineart Incorporation.

Marzuki, A. \& Ying, S. Y. (2017). Environmental monitoring and controlling system for mushroom farm with online interface. International Journal of Computer Science and Information Technology, 9(4), 1728.

Max, R. (2013). Future population growth. Our World in Data. https://ourworldindata.org/future-populationgrowth.

Mohammed, M. F., Azmi, A., Zakaria, Z., et al. (2018). IoT based monitoring and environment control system for indoor cultivation of oyster mushroom. Journal of Physics: Conference Series, 1019, 1-7.

Priya, R. U, Geetha, D. \& Darshan, S. (2016). Biology and cultivation of black ear mushroom-Auricularia spp. Advances in Life Sciences, 5, 10252-10254.

Randive, S. D. (2012). Cultivation and study of growth of oyster mushroom on different agricultural waste substrate and its nutrient analysis. Advances in Applied Science Research, 3(4), 1938-1949.

Rathore, H., Prasad, S., Sharma, S. (2017). Mushroom nutraceuticals for improved nutrition and better human health: A review. PharmaNutrition, 5(2), 35-46.

Rosmiza MZ., Davies, W.P., Rosniza Aznie C.R., et al. (2016). Prospects for increasing commercial mushroom production in malaysia: challenges and opportunities. Mediterranean Journal of Social Sciences MCSER Publishing, 7(1), 406-415.

Ryu, J.-S., Kim, M.K., Im, C.H., et al. (2015). Development of cultivation media for extending the shelf-life and improving yield of king oyster mushrooms (Pleurotus eryngii). Scientia Horticulturae, 193, 121126.

Sharma, S., Yadav, R. K. P. \& Pokhrel, C. P. (2013). Growth and yield of oyster mushroom (Pleurotus ostreatus) on different substrates. Journal on New Biological Reports, 2(1), 3-8.

Stanley, H.O., Umolo, E.A. \& Stanley, C.N. (2011). Cultivation of oyster mushroom (Pleurotus pulmonarius) on amended corncob substrate. Agriculture and biology journal of north America, 2(8), 1239-1243.

Wafi, S.R., Ismail, M. R. \& Ahmed, E. M. (2011). A case study of the climate factor on thermal comfort for hostel occupants in Universiti Sains Malaysia (USM), Penang, Malaysia. Journal of Sustainable Development, 4(5), 50-61.

Copyright (C) 2021 by Teik, T. S. et al. and HH Publisher. This work is licensed under the Creative Commons

Attribution-NonCommercial 4.0 International Lisence (CC-BY-NC4.0) 